\title{
Emotional and behavioral problems: a school-based study in southern Brazil
}

\author{
Problemas emocionais e comportamentais: \\ um estudo de base escolar no sul do Brasil
}

\author{
Suelen de Lima Bach, ${ }^{1}$ (D) Mariane Lopez Molina, ${ }^{1}$ Paulinia Leal do Amaral, ${ }^{1}$ Amanda Neumann Reyes, ${ }^{1}$ \\ Karen Jansen, ${ }^{1}$ Ricardo Azevedo da Silva, ${ }^{1}$ Janaína Vieira dos Santos Motta ${ }^{1}$ (D)
}

\begin{abstract}
Introduction: Mental health assessment in childhood needs to be carried out within a broader context that includes different factors.

Objective: To assess the prevalence of emotional and behavioral problems in schoolchildren and associated factors.

Method: A cross-sectional study was conducted with a schoolbased sample at 20 schools selected by systematic random sampling. Participants consisted of children aged 7-8 year old and their parents or primary caregivers. The Strengths and Difficulties Questionnaire (SDQ) was used to screen for the presence of emotional and behavioral problems in children.

Results: A total of 596 dyads were evaluated. The prevalence of emotional and behavioral problems was 30.0\% among boys and $28.2 \%$ among girls. Hyperactivity/inattention were more prevalent among boys $(p=0.015)$. Belonging to economically disadvantaged strata increased the likelihood of emotional and behavioral problems among schoolchildren by $71 \%(p=0.001)$, while having parents or caregivers with mental disorder increased by 2.2 times that probability $(p<0.001)$.

Conclusion: Our findings showed a high prevalence of emotional and behavioral problems among schoolchildren, as well as the influence of economic conditions and of the mental health of parents and caregivers on child mental health.

Keywords: Schoolchildren, emotional and behavioral problems, child mental health.
\end{abstract}

\section{Resumo}

Introdução: A avaliação da saúde mental na infância necessita ser realizada dentro de um contexto amplo que considere os diferentes fatores envolvidos.

Objetivo: Verificar a prevalência de problemas emocionais e comportamentais em escolares, bem como fatores associados.

Método: Estudo transversal, com amostra de base escolar em que foram selecionadas 20 escolas por amostragem aleatória sistemática. Participaram crianças com 7-8 anos e seus pais ou principais cuidadores. A presença de problemas emocionais e comportamentais nas crianças foi rastreada pelo Strengths and Difficulties Questionnaire (SDQ).

Resultados: Foram avaliadas 596 díades. A prevalência de problemas emocionais e comportamentais foi de $30,0 \%$ entre os meninos e $28,2 \%$ entre as meninas. Sintomas de hiperatividade/ desatenção foram mais prevalentes entre meninos $(p=0,015)$. Pertencer a camadas menos favorecidas economicamente aumentou em $71 \%$ a probabilidade de problemas emocionais e comportamentais entre os escolares $(p=0,001)$, enquanto ter pais ou cuidadores com transtorno mental aumentou 2,2 vezes tal probabilidade $(p<0,001)$.

Conclusões: Nossos achados demonstram a elevada prevalência de problemas emocionais e comportamentais entre escolares, bem como a influência das condições econômicas e da saúde mental de pais e cuidadores sobre a saúde mental infantil.

Descritores: Escolares, problemas emocionais e comportamentais, saúde mental infantil.

\footnotetext{
${ }^{1}$ Programa de Pós-Graduação em Saúde e Comportamento, Universidade Católica de Pelotas, Pelotas, RS, Brazil. Submitted Sep 23 2017, accepted for publication Dec 092018.

Suggested citation: Bach SL, Molina ML, Amaral PL, Reyes AN, Jansen K, Silva RA, et al. Emotional and behavioral problems: a school-based study in southern Brazil. Trends Psychiatry Psychother. 2019;41(3):211-217. http://dx.doi.org/10.1590/2237-6089-2017-0119
} 


\section{Introduction}

Mental health problems affect $10-20 \%$ of children and adolescents in low-income and middle-income countries. ${ }^{1}$ The mental health problems most commonly observed in childhood are conduct disorder, attentiondeficit/hyperactivity disorder and depressive or anxiety disorder. ${ }^{2,3}$

Emotional and behavioral problems are characterized by an inability to establish satisfactory interpersonal relationships with peers, inappropriate behaviors or feelings under normal circumstances, a general pervasive mood of unhappiness or depression, and a tendency to develop physical symptoms or fears associated with personal problems. ${ }^{4}$ These mental problems often become more evident in the school setting and may impair the functional and cognitive performance of schoolchildren. ${ }^{5}$

The World Health Organization (WHO) has pointed out that early detection of vulnerable groups is important because it may prevent developmental impairment and worsening of the clinical condition. ${ }^{6}$ Tracking the prevalence of emotional and behavioral problems among children is the first step in determining their magnitude, but the identification of positive and negative factors that affect child mental health may also guide early interventions for reducing the risk of disorders. ${ }^{1}$

Mental health assessment in childhood needs to be carried out within a broader context. According to Halpern \& Figueiras, ${ }^{7}$ the risk factors that contribute to the emergence and aggravation of mental health problems at this development stage are numerous, complex, and interrelated. In this sense, poverty and social disadvantage are strongly associated with mental health problems in children and adolescents. The literature points out that growing up in economically disadvantaged families increases the risk of exposure to adversity, such as unemployment, severe marital discord, parents with mental health and use of inappropriate educational methods. ${ }^{8}$

Therefore, the present study aimed to assess the prevalence of emotional and behavioral problems in schoolchildren and associated factors so as to improve our knowledge of the mental health reality and related conditions to which public schoolchildren in southern Brazil are exposed.

\section{Method}

This was a cross-sectional study with a school-based sample conducted between August 2015 and November 2016. It is part of a larger project entitled "Healthy childhood in context: a multidisciplinary investigation," designed to study obesity using a multidimensional approach, evaluating psychological, cognitive, motor, nutritional and biological factors. The present study was approved by the research ethics committee of Universidade Católica de Pelotas (UCPel), Pelotas, state of Rio Grande do Sul (RS), southern Brazil (protocol 843.526).

A probabilistic sampling method was used to select the municipal elementary schools (primary sampling units) for the present study. To that end, 20 public elementary schools were randomly selected out of 40 in the urban area of the city of Pelotas. Schoolchildren aged 7-8 years and one of their respective parents or primary caregivers were included in the study.

Inclusion criteria for children were being 7 or 8 years of age and having parents or caregivers who agreed to participate by signing an informed consent form; for parents or caregivers, the only inclusion criterion was to agree to respond to the research instruments. Exclusion criteria were the inability to understand or respond to the instruments due to any clinical condition or severe disability of the child or his/her caregiver. The definition of the children's age group (i.e., 7-8 years) was based on the objectives of the major project, related to motor proficiency tests and cognitive performance, considering the stages of child development.

Data collection involved the following steps: 1) first contact with the school principals and project presentation; 2) children considered eligible for the study were listed; 3) a written informed consent form was sent to parents or caregivers to authorize their participation; 4) once the signed document was returned, children were evaluated in the school setting during school hours; and 5) parents and/or caregivers were interviewed later in their homes. Trained interviewers carried out the evaluations.

Structured questionnaires were used to collect sociodemographic variables (age, gender, skin color, family composition) and specific information about the parents and/or caregivers (age, marital status, current job and schooling). Economic status was measured using the Brazilian National Wealth Index (Indicador Econômico Nacional), which enables to calculate scores (referred to as income terciles) for households based on information on the ownership of a set of assets, household characteristics and the household head's education. ${ }^{9}$

The presence of mental disorders in parents or caregivers was assessed using the Mini International Neuropsychiatric Interview (MINI), a brief standardized diagnostic interview based on criteria from the Diagnostic and Statistical Manual of Mental Disorders, 4th edition (DSM-IV) and the International Classification of Diseases, 10 th revision (ICD-10). ${ }^{10}$ The presence of at least one of the following current diagnoses was 
investigated: depressive disorder, bipolar disorder, panic disorder, agoraphobia, social phobia, obsessivecompulsive disorder, posttraumatic stress disorder, and generalized anxiety disorder.

The presence of emotional and behavioral problems in children was assessed using the Strengths and Difficulties Questionnaire (SDQ), Parent Version. It is a 25-item open access tool (www.sdqinfo.com) used to screen for mental health problems in children and adolescents (4 to 17 years of age) in the last 6 months. The Brazilian version of the SDQ was validated by Fleitlich-Bilyk \& Goodman, ${ }^{11}$ and the psychometric properties proved to be satisfactory. ${ }^{12}$

The SDQ contains 25 items (5 referring to social skills and 20 to difficulties), categorized into 5 scales of 5 items each: emotional symptoms, conduct problems, hyperactivity/inattention, peer problems and pro-social behavior. A total difficulty score can be calculated by summing scores of four difficulties subscales, i.e., except for pro-social behavior. The pro-social behavior scale evaluates resources rather than problems. Thus, its score is not included in the total difficulty score, because a lack of pro-social behavior problems is conceptually different from the presence of psychological difficulties. ${ }^{13}$ The SDQ enables researchers to classify subjects as normal, borderline, or abnormal, based on cutoff points. For this study, the abnormal category (scores 17-40) was adopted to determine the presence of emotional and behavioral problems. ${ }^{11}$

Data were typed twice, with subsequent review to assess possible errors, including automatic checks for consistency and amplitude, using the program EpiData Entry version 3.1. Data analysis was performed in the Statistical Package for the Social Sciences (SPSS) version 22.0. Significance levels were maintained at 5\% in all analyses. Data were described using absolute and relative frequency distributions.

Bivariate analysis was conducted through the chisquare test. Multivariate analysis was performed using Poisson regression. Poisson regression with robust estimative of variance is a better alternative for the analysis of cross-sectional or longitudinal studies with binary outcomes than logistic regression when outcomes are frequent, because the odds ratio can strongly overestimate the prevalence ratio. ${ }^{14}$ In the adjusted analysis, all variables with a bivariate statistical significance of $p<0.2$ were included.

\section{Results}

A total of 723 children were considered eligible for inclusion in this study. Among these, 34 (5\%) did not attend school on the evaluation days, and $80(11 \%)$ parents declined participation on behalf of their children, resulting in a total of 609 children who responded to the assessment instruments. Of the parents or primary caregivers, 13 were not located or refused to participate in the study. Thus, 596 dyads were included in the analysis.

Among the schoolchildren, $55.7 \%$ were 8 years old, $63.4 \%$ had white skin color and $62.1 \%$ lived with both parents. Regarding the parents' or caregivers' characteristics, $67.6 \%$ were $\geq 31$ years, $73.1 \%$ lived with a partner, $53.1 \%$ were working at the time of the interview, and $50.2 \%$ had up to 8 years of education. Concerning the presence of mental disorders in the caregivers, $40.3 \%$ showed at least one of the following current diagnoses: depressive disorder, bipolar disorder, panic disorder, agoraphobia, social phobia, obsessivecompulsive disorder, posttraumatic stress disorder, and generalized anxiety disorder (Table 1).

The prevalence of emotional and behavioral problems in schoolchildren was $30.0 \%$ among boys and $28.2 \%$ among girls. The prevalence of hyperactivity/ inattention symptoms was higher in boys (39.5\%) than in girls $(30.0 \%)(p=0.015)$. There was no significant difference between genders among the other emotional and behavioral problems evaluated (Figure 1).

In the crude analysis, the prevalence of the outcome was higher in children with non-white skin color $(p=0.003)$, whose parents or caregivers were $\leq 30$ years old $(p=0.005)$, were not working at the time of the interview $(p=0.031)$, had up to 8 years of education $(p<0.001)$, were classified as lower income $(p<0.001)$ and had a current diagnosis of mental disorder $(p<0.001)$.

In the adjusted analysis, economic classification and mental health status of parents or caregivers remained associated with the outcome. Thus, belonging to lowerincome strata increased the probability of emotional and behavioral problems among schoolchildren by $71 \%(p=0.001)$ and having parents or caregivers with current mental disorder increased by 2.2 times the probability for such problems in this sample (Table 2 ). It should be noted that the variable referring to caregiver education was not included in the adjusted model due to collinearity.

\section{Discussion}

The present study investigated emotional and behavioral problems in 7- and 8-year-old schoolchildren and found a high prevalence of mental health problems in this non-clinical sample. Hyperactivity/inattention 
symptoms proved to be more prevalent among boys, and emotional symptoms among girls. In addition, effects were observed of economic conditions and mental health of parents and caregivers on child mental health.

In our sample, a higher prevalence of hyperactivity/ inattention symptoms was found among boys. Cury \& Golfeto ${ }^{15}$ also identified significantly higher means among boys in the hyperactivity/inattention subscale when compared to girls, but the results of Becker et al. did not show such difference. ${ }^{16}$ We also observed a tendency for a higher prevalence of emotional symptoms among girls, and previous studies have demonstrated a significant effect of gender on this category of problems in children of the same age group. ${ }^{17}$ However, given the inconsistent differences in the proportion of emotional and behavioral problems between genders, we understand that these results should be considered with wariness.

The high prevalence observed for total emotional and behavioral problems was above that demonstrated in another national research conducted in the Southeast region, namely $18.7 \%,{ }^{15}$ but below the one found in the Northeast by Rodriguez et al. of $47.7 \% .^{18}$ Both studies used the SDQ to assess mental health problems in children. The inclusion of children of different age groups and the sociocultural characteristics of the

Table 1 - Characteristics of schoolchildren and their respective parents or caregivers, Pelotas, RS, 2015-2016 ( $n=596)$

\begin{tabular}{|c|c|c|c|}
\hline Variable & Total, n (\%) & Boys, n (\%) & Girls, n (\%) \\
\hline \multicolumn{4}{|l|}{ Schoolchildren } \\
\hline \multicolumn{4}{|l|}{ Age (years) } \\
\hline 7 & $264(44.3)$ & $125(40.5)$ & $139(48.4)$ \\
\hline 8 & $332(55.7)$ & $184(59.5)$ & $148(51.6)$ \\
\hline \multicolumn{4}{|l|}{ Skin color } \\
\hline White & $378(63.4)$ & $200(64.7)$ & $178(62.0)$ \\
\hline Non-white & $218(36.6)$ & $109(35.3)$ & $107(38.0)$ \\
\hline \multicolumn{4}{|l|}{ Lives with } \\
\hline Both parents & $370(62.1)$ & $202(65.4)$ & $168(58.5)$ \\
\hline Only mother & $186(31.2)$ & $83(26.9)$ & $103(35.9)$ \\
\hline Only father & $18(3.0)$ & $11(3.6)$ & $7(2.4)$ \\
\hline Other caregiver & $22(3.7)$ & $13(4.2)$ & $9(3.1)$ \\
\hline \multicolumn{4}{|l|}{ Parents or caregivers } \\
\hline \multicolumn{4}{|l|}{ Age (years) $)^{*+}$} \\
\hline$\leq 30$ & $193(32.4)$ & $102(33.0)$ & $91(31.8)$ \\
\hline$\geq 31$ & $402(67.6)$ & $207(67.0)$ & $195(68.2)$ \\
\hline \multicolumn{4}{|l|}{ Lives with partner* } \\
\hline No & $160(26.9)$ & $81(26.2)$ & $79(27.5)$ \\
\hline Yes & $435(73.1)$ & $227(73.7)$ & $208(72.5)$ \\
\hline \multicolumn{4}{|l|}{ Current work* } \\
\hline No & $279(46.9)$ & $140(45.5)$ & $139(48.4)$ \\
\hline Yes & $316(53.1)$ & $168(54.5)$ & $148(51.6)$ \\
\hline \multicolumn{4}{|l|}{ Education (years) } \\
\hline$\leq 8$ & $299(50.2)$ & $151(48.9)$ & $148(51.6)$ \\
\hline $9-11$ & $206(34.6)$ & $108(35.0)$ & $98(34.1)$ \\
\hline$\geq 12$ & $91(15.3)$ & $50(16.2)$ & $41(14.3)$ \\
\hline \multicolumn{4}{|c|}{ Economic indicator (tercile) } \\
\hline Lower & $199(33.4)$ & $100(32.4)$ & $99(34.5)$ \\
\hline Intermediate & $199(33.4)$ & $100(32.4)$ & $99(34.5)$ \\
\hline Upper & $198(33.2)$ & $109(35.3)$ & $89(31.0)$ \\
\hline \multicolumn{4}{|c|}{ Current mental disorder* } \\
\hline No & $353(59.7)$ & $188(61.2)$ & $165(58.1)$ \\
\hline Yes & $238(40.3)$ & $119(38.8)$ & $119(41.9)$ \\
\hline Total & $596(100)$ & $309(51.8)$ & $287(48.2)$ \\
\hline
\end{tabular}

* Responses missing.

${ }^{+}$Statistically significant difference between genders: chi-square test, $p=0.003$. 
samples may possibly explain the differences in the proportion of behavioral and emotional problems in childhood found across all three studies. Despite such differences, our findings showed an early onset of emotional and behavioral impairments in schoolchildren in the first elementary school years.

Comparing to the international literature, the prevalence of emotional and behavioral problems found in our study was high. Elberling et al., for instance, found a $4.8 \%$ for total problems. ${ }^{19}$ Our findings demonstrated an association between the presence of emotional and behavioral problems and socioeconomic conditions, 5,18,19 suggesting that some risk factors for mental health problems in developing countries may be similar to those in economically developed countries, despite the differences in the prevalence of the outcome. ${ }^{1}$

A recent systematic review has pointed out that remaining economically disadvantaged over time was strongly related to higher rates of mental health problems in children and adolescents; in addition, a decrease in socioeconomic status was associated with increasing mental problems. ${ }^{20}$ Better economic conditions may provide greater access to leisure activities and health services, and therefore opportunities to the development of healthy children. In addition, the socioeconomic conditions of the family are usually related to the education of parents or caregivers and income factors that may be related to their own mental health. ${ }^{21}$

Emotional and behavioral problems were associated with the presence of mental disorder in parents or caregivers. Goodman et al. ${ }^{17}$ identified the presence of parental stress as a risk factor for mental health problems in childhood. Similarly, Flouri et al. demonstrated that emotional symptoms and behavioral problems were largely explained by poorer parental mental health among children in the United Kingdom. ${ }^{5}$ Finally, Hancock et al. found higher scores on the instrument used to screen for mental suffering in children whose parents had mental health problems. ${ }^{22}$

Previous studies have shown that the environmental factors affecting child development, especially parental mental health, as demonstrated by our findings, were strongly involved in their mental health condition. ${ }^{21-23}$ Some of those studies focused on depression or other maternal mental disorder as a negative influence on the interaction with children and consequent social and emotional damages to them. ${ }^{24}$ This is an important aspect of our results, considering that virtually all those interviewed were biological mothers.

The cross-sectional design of the present study can be considered a limitation that makes it difficult to determine a causal direction. Also, even though SDQ is widely used in research around the world $2,17,25$ and has been validated for the Brazilian population, the fact that parents and/or caregivers were the only informants can be considered another limitation of the present study - the SDQ has a version for teachers. We understand that teachers are privileged observers of the interaction between peers (one of the subscales evaluated by the instrument), as well as of possible hyperactivity/ inattention symptoms, due to the characteristic structure of school activities that require focus and concentration. ${ }^{26}$ Still, the version for teachers was not used due to non-authorization by school authorities.

Conversely, it is worth highlighting that sample representativeness was one of the strengths of the

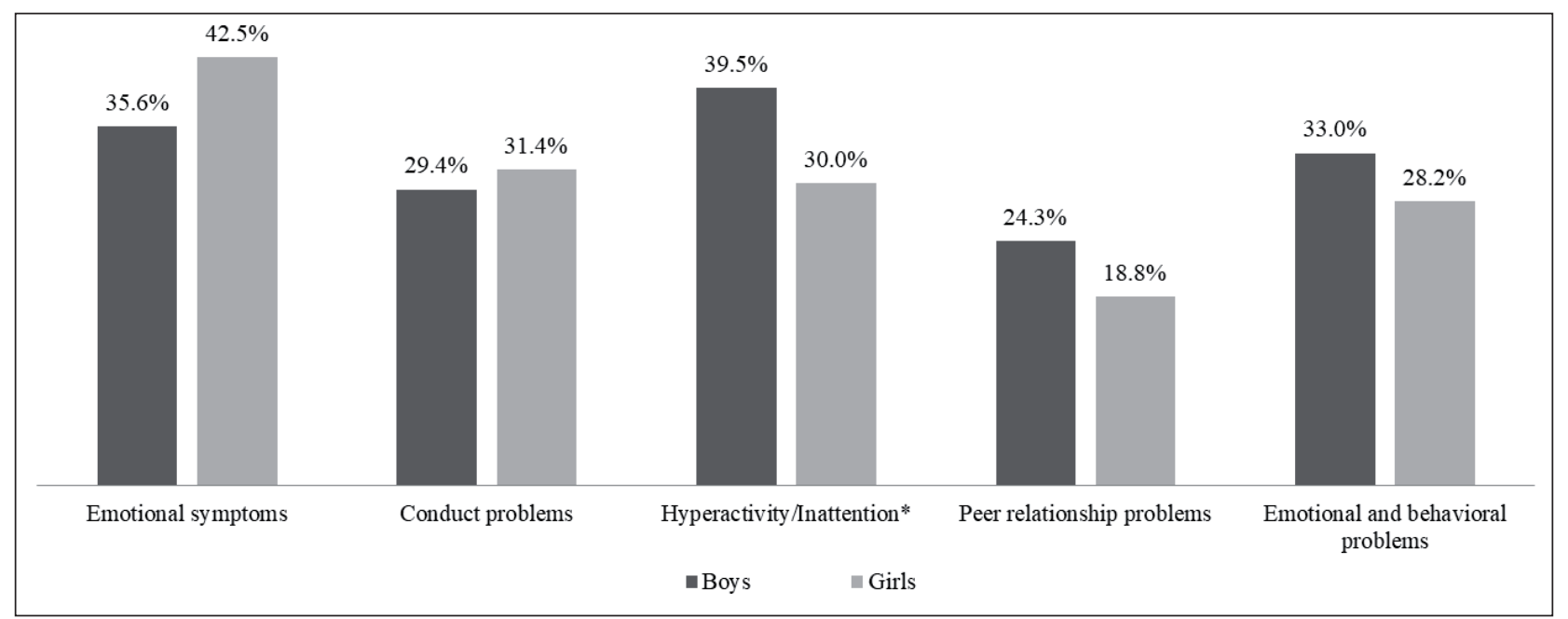

Figure 1 - Prevalence rates of emotional and behavioral problems according to gender in schoolchildren, Pelotas, RS, 2015-2016 $(n=596) . * p=0.015$. 
present investigation. In other words, the findings were representative of public schoolchildren aged 7-8 years, and improved our knowledge of their mental health condition. Another relevant aspect was the use of the MINI to identify mental disorders in parents or caregivers.

The high prevalence of emotional and behavioral problems found among 7-8-year-old schoolchildren suggests that special attention should be given to the mental health of this population. It also revealed the relevance of understanding health more broadly: not merely as the absence of disease, but rather as a multiplicity of factors that may affect child development.

Our findings highlighted the influence of economic conditions and the mental health of parents and caregivers on children's emotions and behaviors, demonstrating the need for preventive psychological care services, offering quality assistance free of charge. In this sense, public policies should consider the school as a useful environment for the early detection of possible impairments in child mental health.

Table 2 - Factors associated with emotional and behavioral problems in schoolchildren and their respective parents or caregivers, Pelotas, RS, 2015-2016 $(n=596)$

\begin{tabular}{|c|c|c|c|c|c|}
\hline Variable & n (\%) & Crude PR (95\%CI) & p-value & Adjusted PR (95\%CI) & p-value \\
\hline \multicolumn{6}{|l|}{ Schoolchildren } \\
\hline Age (years) & & & 0.470 & & - \\
\hline 7 & $77(29.2)$ & Reference & & - & \\
\hline 8 & $106(31.9)$ & $1.09(0.86-1.40)$ & & - & \\
\hline Skin color & & & 0.003 & & 0.071 \\
\hline White & $100(26.5)$ & Reference & & Reference & \\
\hline Non-white & $83(38.1)$ & $1.44(1.13-1.83)$ & & $1.23(0.98-1.53)$ & \\
\hline Lives with & & & 0.230 & & - \\
\hline Both parents & $108(29.2)$ & Reference & & - & \\
\hline Only mother & $61(32.8)$ & $1.12(0.87-1.46)$ & & - & \\
\hline Only father & $5(27.8)$ & $0.95(0.44-2.04)$ & & - & \\
\hline Other caregiver & $9(40.9)$ & $1.40(0.83-2.37)$ & & - & \\
\hline \multicolumn{6}{|l|}{ Parents or caregivers } \\
\hline Age (years)* & & & 0.005 & & 0.068 \\
\hline$\leq 30$ & $74(38.3)$ & $1.41(1.11-1.80)$ & & $1.23(0.98-1.54)$ & \\
\hline$\geq 31$ & $109(27.1)$ & Reference & & Reference & \\
\hline Lives with partner* & & & 0.678 & & - \\
\hline No & $51(31.9)$ & $1.06(0.81-138)$ & & - & \\
\hline Yes & $131(30.1)$ & Reference & & - & \\
\hline Current work* & & & 0.031 & & 0.401 \\
\hline No & $98(35.1)$ & $1.30(1.02-1.66)$ & & $1.10(0.88-1.38)$ & \\
\hline Yes & $85(26.9)$ & Reference & & Reference & \\
\hline Education (years) & & & $<0.001$ & & - \\
\hline$\leq 8$ & $117(39.1)$ & $2.74(1.62-4.62)$ & & - & \\
\hline $9-11$ & $53(25.7)$ & $1.80(1.03-3.14)$ & & - & \\
\hline$\geq 12$ & $13(14.3)$ & Reference & & - & \\
\hline Economic indicator (tercile) & & & $<0.001$ & & 0.001 \\
\hline Lower & $90(45.2)$ & $2.63(1.87-3.71)$ & & $1.71(1.21-2.42)$ & \\
\hline Intermediate & $59(29.6)$ & $1.73(1.19-2.51)$ & & $1.38(0.95-2.00)$ & \\
\hline Upper & $34(17.2)$ & Reference & & Reference & \\
\hline Current mental disorder* & & & $<0.001$ & & $<0.001$ \\
\hline No & $65(18.4)$ & Reference & & Reference & \\
\hline Yes & $116(48.7)$ & $2.65(2.05-3.42)$ & & $2.24(1.73-2.90)$ & \\
\hline Total & $183(30.7)$ & - & & - & \\
\hline
\end{tabular}

$95 \% \mathrm{CI}=95 \%$ confidence interval; $\mathrm{PR}=$ prevalence ratio.

* Responses missing. 


\section{Acknowledgements}

This research received financial support from Conselho Nacional de Desenvolvimento Científico e Tecnológico (CNPQ) and Fundação de Amparo à Pesquisa do Estado do Rio Grande do Sul (FAPERGS).

\section{Disclosure}

No conflicts of interest declared concerning the publication of this article.

\section{References}

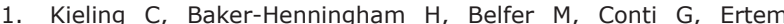
$\mathrm{I}$, Omigbodun $\mathrm{O}$, et al. Child and adolescent mental health worldwide: Evidence for action. Lancet. 2011;378:1515-25.

2. Adriaanse $M$, van Domburgh $L$, Zwirs $B$, Doreleijers $T$, Veling $W$. School-based screening for psychiatric disorders in MoroccanDutch youth. Child Adolesc Psychiatry Ment Health. 2015;9:13.

3. Petresco S, Anselmi L, Santos IS, Barros AJD, Fleitlich-Bilyk $B$, Barros FC, et al. Prevalence and comorbidity of psychiatric disorders among 6-year-old children: 2004 Pelotas Birth Cohort. Soc Psychiatry Psychiatr Epidemiol. 2014;49:975-83.

4. Laudrum T. Emotional and behavioral disorders. In: Kaufmfman JM, Hallahan DP, Pullen PC, editors. Handbook of special education. 2nd ed. New York: Routledge; 2017. p. 28-32.

5. Flouri E, Mavroveli S, Tzavidis N. Cognitive ability, neighborhood deprivation, and young children's emotional and behavioral problems. Soc Psychiatry Psychiatr Epidemiol. 2012;47:985-92.

6. World Health Organization. The World Health Report 2001: Mental health, new understanding, new hope. Geneva: WHO; 2001.

7. Halpern R, Figueiras ACM. Environmental influences on child mental health. J Pediatr (Rio J). 2004;80:S104-10

8. Camargo Vitolo YL, Fleitlich-Bilyk B, Goodman R, Bordin IAS. Crenças e atitudes educativas dos pais e problemas de saúde mental em escolares. Rev Saude Publica. 2005;39:716-24.

9. Barros AJD, Victoria CG. Indicador econômico para o Brasil baseado no censo demográfico de 2000. Rev Saude Publica. 2005;39:523-9.

10. Amorim P. Mini International Neuropsychiatric Interview (MINI): validação de entrevista breve para diagnóstico de transtornos mentais. Braz J Psychiatry. 2000;22:106-15.

11. Fleitlich-Bilyk B, Goodman R. Prevalence of child and adolescent psychiatric disorders in southeast Brazil. J Am Acad Child Adolesc Psychiatry. 2004:43:727-34.

12. Woerner W, Fleitlich-Bilyk B, Martinussen R, Fletcher J, Cucchiaro $G$, Dalgalarrondo $P$, et al. The Strengths and Difficulties Questionnaire overseas: evaluations and applications of the SDQ beyond Europe. Eur Child Adolesc Psychiatry. 2004;13 Suppl 2:II47-54.

13. Goodman R. The strengths and difficulties questionnaire: a research note. J Child Psychiatr. 1997;5:581-6.

14. Barros AJD, Hirakata VN. Alternatives for logistic regression in cross-sectional studies: an empirical comparison of models that directly estimate the prevalence ratio. BMC Med Res Methodol. 2003;3:21.

15. Cury CR, Golfeto JH. Strengths and Difficulties Questionnaire (SDQ): a study of school children in Ribeirão Preto. Braz J Psychiatry. 2003;25:139-45.

16. Becker A, Lorenzo MJ, Ralston SJ, Rothenberger A, Rothenberger PA. Psychopathological screening of children with ADHD: Strengths and Difficulties Questionnaire in a pan-European study. Eur Child Adolesc Psychiatry. 2006;62:56-62.

17. Goodman A, Fleitlich-Bilyk B, Patel V, Goodman R. Child, family, school and community risk factors for poor mental health in Brazilian schoolchildren. J Am Acad Child Adolesc Psychiatry. 2007;46:448-56.

18. Rodriguez JDM, Silva AAM, Bettiol H, Barbieri MA, Rona RJ. The impact of perinatal and socioeconomic factors on mental health problems of children from a poor Brazilian city: A longitudinal study. Soc Psychiatry Psychiatr Epidemiol. 2011;46:381-91.

19. Elberling $H$, Linneberg $A$, Olsen EM, Goodman $R$, Skovgaard AM. The prevalence of SDQ-measured mental health problems at age 5-7 years and identification of predictors from birth to preschool age in a Danish birth cohort: The Copenhagen Child Cohort 2000. Eur Child Adolesc Psychiatry. 2010;19:725-35.

20. Hancock KJ, Mitrou F, Shipley M, Lawrence D, Zubrick SR. A three generation study of the mental health relationships between grandparents, parents and children. BMC Psychiatry. 2013;13:299.

21. Cid MFB, Matsukura TS. Problemas de saúde mental em escolares e seus responsáveis: um estudo de prevalência. Rev Ter Ocup Univ Sao Paulo. 2014;25:1-10.

22. Ferriolli SHT, Marturano EM, Puntel LP. Contexto familiar e problemas de saúde mental infantil no Programa Saúde da Família. Rev Saude Publica. 2007;41:251-9.

23. Sá D, Bordin I, Martin D, Paula C. Fatores de risco para problemas de saúde mental na infância/adolescência. Psicol Teor Pesq. 2010;26:643-52.

24. Mendes AV, Loureiro SR, Crippa JA. Depressão materna e a saúde mental de escolares. Rev Psiq Clin. 2008;35:178-86.

25. Anselmi $L$, Fleitlich-Bilyk B, Menezes AMB, Araújo CL, Rohde LA. Prevalence of psychiatric disorders in a Brazilian birth cohort of 11-year-olds. Soc Psychiatry Psychiatr Epidemiol. 2010;45:13542 .

26. Duarte CS, Bordin IA. Instrumentos de avaliação. Braz ] Psychiatry. 2000;22:55-8.

\section{Correspondence:}

Janaína Vieira dos Santos Motta

Universidade Católica de Pelotas

Rua Gonçalves Chaves, 377, sala 411, prédio C

96015-560 - Pelotas, RS - Brazil

Tel.: +55 (53) 21288404

E-mail: janaina.motta@ucpel.edu.br 